\title{
DISABILITY AND VULNERABILITY - IMPEDIMENTS OR POSSIBILITIES? A Hypothesis from the scope of social Christian ethics
}

\section{Introduction}

The visible condition of a person in bodily pain or of a person who has lost autonomy, social status or self-representation, reveals to some degree an invisible reality which is present in every human being. In other words, in the encounter with a marginal, dependent, sick or disabled person, moral judgements based on the idea of independence and autonomy are often revealed to be illusions, challenged by the idea of dependent, deeply vulnerable and limited creatures. ${ }^{1}$

Assuming the validity of this premise, my primary purpose in the following paper is first to reflect upon social and cultural attitudes that consider disability and vulnerability as a boundary and a threat; and secondly, to propose an alternative in transgressing the differences of socio - anthropological boundaries in order to enable dynamic communication with fellow human beings, and ultimately, to bring about true human flourishing.

In the first part of this paper I will reflect upon the meaning of disability, as well as, the impact that the presence of those living with disability has on individuals and society at large. In such perspective, particular emphasis laid upon the physical condition of those living with disability. In the second part, my focus will be on the meaning of vulnerability associated with, but distinct from the notion of disability. Thirdly, I will elucidate my argument with concrete examples from the L'Arche community — where people with and without disabilities are living together in mutual interdependency and cooperation.

* Martina Vuk, E-Mail: martina.vuk@unifr.ch, Université de Fribourg, Switzerland \& FNS — Doc.Mobility, Fellow, University of Aberdeen, UK.

1 John Swinton, Becoming Friends of Time: Disability, Timefulness, and Gentle Discipleship (Texas, Baylor University Press, 2016). 


\section{What is disability?}

Definitions of disability ${ }^{2}$ depend on whether disability is approached from the realm of biomedical or social sciences. Numerous definitions of disability have been proposed in an academic framework within the last fifty years stemming from medical through to a social definition. According to a recent World Health Organization (WHO) definition - also used in our European context - disability is considered an umbrella term that covers impairments, activity limitations, and participation restrictions. ${ }^{3}$ Disability is thus not just a health problem, it is a complex phenomenon reflecting the interaction between features of a person's body and features of the society in which he or she lives. Overcoming the difficulties faced by people with disability, requires interventions to remove environmental and social barriers. When approaching disability discourses from the scope of Disability studies, ${ }^{4}$ two dominant models ${ }^{5}$ are discussed: the biomedical and social model. Those two models have been largely influential in framing the definition of disability, as presented above. The biomedical model, on the one hand, looks at disability as a physical condition and individual tragedy that needs to be fixed or cured by medical intervention. The social model, on the other hand, emerged as a reaction to the biomedical model in the early 1970s. Its primarily focus is on "fixing" societal attitudes towards disabled people, instead

2 In this paper, my reflection does not include a particular type of disability, such as severe, developmental or intellectual. I will use them interchangebly. My emphasis is to illuminate an interdisciplinary conceptual and cultural comprehension of disability understood within the context of mainstrem society. For a more robust comprehension and classification of disability see: World Health Organisation, World Report on Disability, (Geneva: World Health Organisation, 2011), available from http: // www.who.int / disabilities/ world_report/2011/report.pdf ; World Health Organisation, International Classification of Functioning, Disability and Health (ICF), (Geneva: World Health Organisation, 2001), available from http://www.who.int/classifications/icf/en/; See also "Definition on Developmental and Intellectual Disability," American Association on Intellectual and Developmental Disability (AAIDD), available from http://aaidd.org/home

3 See "Disabilities,” World Health Organisation, accessed April 2017, available from http: // www.who.int/ topics/disabilities/en/

4 According to one of its proponents and as a person with direct experience of impairment, Simi Linton defines Disability studies as the socio-political-cultural model of disability incarnate. It provides an epistemology of inclusion and integration, formulating ideas that could not have been imagined from the restrictive thresholds of the traditional cannon. See Simi Linton, "Disability Studies/Not Disability Studies,” Disability\&Society, Vol. 13, no.4.,1998.

5 Alongside two dominant models of disability, there are few other approaches to disability such as: radical model (Whithers, 2012); human rights model, (UN, 2006); or few versions of social model such as British Social Model, (Campbell\&Oliver,1998; Barnes\&Mercer, 2010); the North American minority approach (Scotch, 1984); the Nordic relational model (Tøssebro 2002, 2004); postmodernist disability approach (Corker\&Shakespeare, 2002), etc. 
of looking on disability as physical impairment. This is to say that for the social model it is society that oppresses people with disabilities by disabling their potential and participation within society, whereas for the biomedical model disability represents a bodily condition called physical impairment which became a plea for medical intervention. Although the two models are rather separated, my suggestion is that in order to establish a holistic understanding of disability, both models - biomedical and social — need to be integrated, yet distinguished. Speaking of disability as a physical impairment, for instance, disability indeed presents a personal or interior boundary to those with disabilities in performing daily tasks, and in communicating or engaging with a "proper" level of social functioning. Likewise, disability as visible condition can also present an unpleasant condition and create hostile attitudes from society and culture towards those living with disabilities. In the first case, it is an individual interior condition of disability such as chronic pain, lack of access or communication that creates a difficulty for the individual. In the second example, it is the society whose attitudes towards disability, for them, disables people with disability on a larger scale by denying their proper inclusion and participation as fellow human beings equal in rights and dignity.

\subsection{Disability, culture, theology}

On the cultural level, with a great effort of social activism there has been unprecedented receptivity towards disability in the modern period. Thanks to the social model definition of disability, which has a broader application within social policies for the disabled, persons have generally become less isolated by being further included in broader society. With the progress of modern medicine many people with disabilities, especially those with Down Syndrome, will experience, as never before, so many benefits with a modern way of practicing medicine. ${ }^{6}$ However, the persistent problem with a western liberal society regarding disability is that people with disability are reduced to the acquisition of rights and freedoms. Although people with disability nowadays can experience inclusion, they do not necessarily feel that they belong or are desired as potential friends, companions or employees. To truly belong one needs to be missed. As theologian John Swinton wrote: "belonging goes deeper than inclusion, since to belong one needs

6 For instance, in an American study on disability the findings of Henry J. Kaiser Family Foundation in 2003 and 2004 have shown that a majority (82\%) people with disability surveyed in a report, think they have better lives today than they had some years ago. However, almost $40 \%$ believed that the health care system treats persons with physical disability unfairly. See "Americans' Views of Disability. A Kaiser Health Poll Report 2004." Henry J. Kaiser Family Foundation, accessed Mai 2015, available from https://www.kff.org 
to be truly seen as one self, while to be included, persons just need to be present in order that the system conform one to some kind of relational, social or legal norm."7 This raises the question: are people with disabilities truly acknowledged as missing within society? The significance of such openness is undermined by evidence of different opinions in academia and in practice (conceptually and socially) regarding the meaning of disability, which reinforces a divisive and discriminatory approach to a person with disability. Conceiving of disability per se and as a concept, as a painful and isolated human existence, in my observation, creates four principal difficulties. First, it establishes a boundary line of interaction between the disabled and the "non-disabled," based upon the fear of interaction and the struggle to encounter the disabled as other, equal in rights and dignity. I call this the psychological stigma impacted by fear and separation. Second, it creates an assumption that the disabled ought to be cured and made normal. Such attitudes reflect the tendency towards individual / biomedical model and normality. The third temptation, as theologian Pia Matthews wrote, is perhaps the one that links disabled children with angelic appearances (or angels) as if they do not quite belong in the earthly realm. ${ }^{8}$ This I call the disembodiment and spiritualization of disabled people. The fourth difficulty when speaking about disability is that encounter with disabled person (as this has been the case in the past, and still continues) provokes within mainstream society the feeling of pity and charity. This has been evident within the scope of social and charitable organizations including the framework of the preferential option of the poor within the catholic Church.

Disability certainly provokes society into displaying a particularly negative and impersonal reaction towards those who live with it. These reactions and stereotypes make it extremely difficult for people to find and maintain positive interpersonal relationships - an important source of value and self-esteem available to everyone.

Regarding the context of the experience of disability, I would suggest that the real question is not whether disability is a social or medical condition, or what cultural images it inflicts, but whether the encounter with a person with disability can be an encounter with a true and different other, equal in dignity and rights, without falling into categorization?

Remedying this situation requires an open approach to elucidate a proper understanding of disability, and more profoundly, a commitment to explore what it means to be human. The theological quest of disability as ity and Humanness" Journal of Religion, Disability and Health. Vol. 16, 2, 2012., p. 184

8 Pia Matthews, Pope John Paul II and the Apparently "Non-acting "Person (Gracewing: Herefordshire, 2013) p. 164. 
Stanley Hauerwas addresses, is not only what theologians or society can do about disable people within society, but why society perceives disability as a problem or an ethical dilemma in the first place. ${ }^{9}$ This means that disability is not merely a concept that must be discussed, and neither is it the condition that requires charity, but it is a theo-anthropological quest that requires a proper reflection of what it means to be made in the image of God and how those whose bodily or rational capacities are lower fit into such a framework.

According to a Christian understanding, being made in the image of God does not explicitly imply having the capacity for rational endeavor or function as 'normal' in terms of modern mainstream projection of normality. The image of God is a deeper category where the relational, preceding the rational, is perceived as a persons' capacity to participate in relational charity with God and other human fellows. This entails that persons with disability as with any other non - disabled person should be respected in their dignity and freedom before being regarded as an object of charitable activity, altruism or moral "obligation." The body and the person belong together and both are called in the human being to imitate Christ. Thus, the discourses on disability not only opens up an important debate within the field of theological anthropology but requires a comprehension of a distinction between disability as a concept or condition from the person that lives with disability. In other words, as a condition, disability presents certain challenges that affect a person's capacity and ability, but the person with disability is not merely her/his disability neither is the person without disability explicitly valued according to his/her ability. My suggestion is that it is not merely disability that needs to be transgressed or overcome, but rather the mainstream attitudes towards disability - that close up in fear and isolation or a feeling of pity and charity, and consequently mark people with disability as vulnerable and dependent.

\section{Vulnerability - common and invisible aspect of humanness?}

This leads us towards the second notion that requires reflection within the scope of this paper - the notion of vulnerability. For the most of history, disability as a condition has been associated with the meaning of vulnerability and stigma. In forms of legal or socio - political language people with disability are frequently situated under the category of vulnerable individuals.

9 Stanley Hauerwas, Suffering Presence: Theological Reflections on Medicine, the Mentally Handicapped and the Church (University of Notre Dame Press: IL,1986). 
This has been evident in many international documents including the United Nations Universal Declaration on Bioethics and Human Rights (art. 8); ${ }^{10}$ the Document on Biomedical Research Involving Human Subjects (CIOMS, 2010); ${ }^{11}$ and the most recent one, the Report of the International Bioethics Committee of UNESCO on the Principle of Respect for Human Vulnerability and Personal Integrity (IBC, 2013). ${ }^{12}$

What about other people? Does vulnerability as a condition also include "the category of normal" or people without disability?

Disability does indeed imply personal vulnerability, as people with disability (with profound or severe disabilities, respectively) do need more attention, affection, understanding and love. However, people with disability cannot be identified or reduced to the meaning of vulnerability as one group of vulnerable individuals, neither can the mainstream population be deprived of the experience of vulnerability. As humans we all are vulnerable, but at the same time we all are autonomous. The real question is what does autonomy precisely mean and why within the modern moral discourse has it been the dominant idea regarding the meaning of being human? The emphasis upon autonomy understood as the capacity of being a self-dependent or rationally powerful creature obscures the recognition of vulnerability as being equally important and constitutive for the realization of human. Vulnerability became a mark of women and children, as well as, the marginal, weak, sick and disabled individuals. Until recently, the meaning of vulnerability was emphasized as a mark of those individuals who are particularly affected by greater bodily vulnerabilities such as people with intellectual disabilities and mental disorders, people with Alzheimer disease or any other individuals whose cognitive abilities are diminished. For this reason, I suggest we take a look at the semantics of the term vulnerability and secondly, on its application within the field of academia.

In the contemporary discourse the meaning of vulnerability is often replaced with the meaning of fragility, weakness and suffering. Although the distinction between the three meanings is subtle, there is an obvious conceptual difference between the abovementioned terms. Vulnerability is not merely the capacity to be wounded, weak and fragile as most relevant dic-

10 See United Nations, Respect for Human Vulnerability and Personal Integrity, (Paris, UNESCO, 2005), Article 8., accessed February, 2014, available from http://portal.unesco.org/ en/ev.php URL_ID $=31058 \& U R L$ DO_TOPIC\&URL_SECTION $=201 . h t m l$

11 See CIOMS, International Ethical Guidelines for Biomedical Research Involving Human Subjects, (Geneva, WHO, 2010), assessed March,2014, available from http: //www.recerca. uab.es/ceeah /docs/CIOMS.pdf., assessed March,2014.

12 United Nations, Report of the International Bioethics Committee (IBC) of Unesco on the Principle of Respect for Human Vulnerability and Personal Integrity, (Paris, UNESCO, 2013), accessed August, 2017, available from http://unesdoc.unesco.org/ images/0018/001895/189591e.pdf. 
tionaries will describe it. Neither is it a tragic condition of illness and suffering, which has been reflected within various contemporary discourses. Yet, it is a complex and controversial term which require proper clarification.

Besides acknowledging vulnerability as the capacity to be wounded, The Dictionnaire Encyclopédique $D^{\prime}$ Ethique Chretienne ${ }^{13}$ defines vulnerability as a form or mode of human existence embedded in vitality, sensitivity and sociability. The present dictionary also acknowledges vulnerability as a phenomenon that manifests itself through sad emotions (anxieties, despair and dislike) in periods of insecurity, violence, or death. In her book La vulnérabilité une nouvelle catégorie morale?14 Swiss philosopher Nathalie Maillard addresses vulnerability as a term relevant to living beings as their ontological category which by nature of things per se, constitutes an essential part of their existence. It is important to emphasize that according to Maillard definition, although all living beings are substantially vulnerable, not all have the same intensity of vulnerability. There are people who are more vulnerable (for instance people with disability) and people who react differently on vulnerability. This means that we cannot make a categorical distinction between vulnerable and non-vulnerable individuals, but between more or less vulnerable people.

The second issue I would like to emphasize regarding vulnerability is its implications and understanding within academic disciplines. Within the scope of academia, the most recent ethical, philosophical and theological discourses have shown that vulnerability can be approached from various perspectives and dimensions. The medical approach seemingly locates the notion of vulnerability within the notion of disease - corporeal and biological susceptibility. In bioethical discourses, priority has been given to the discussion regarding the relation between the concerns of autonomy and vulnerability ${ }^{15}$ and as a reaction to medical and technological power and control.

In the context of social philosophy, the notion is that vulnerability implies social, environmental, political and economic individual disadvantages, such as malnutrition, migration, poverty, abuse, etc. The philosophical and theological literature distinguishes vulnerability as an ontological condition, anthropologically conceptualized within the context of life experience, and discussed as a mutual human and a human - Divine interChretienne. Paris: Les Editions du Cerf, 2013.

14 Nathalie Maillard, La vulnérabilité une nouvelle catégorie morale? (Genève: Labor et Fides, 2011), p. 161-228.

15 See Barry Hoffmaster, "What does vulnerability mean?," Hasting Center Report, 36, no. 2, (2006); Michael H.Kottow. "The vulnerable and the Susceptible," Bioethics, 17 no.5 (2003). 
dependence. ${ }^{16}$ Following such propositions, my further focus concerns the relational aspect of vulnerability, as a theo-anthropological concept, and acknowledges vulnerability as a human condition given to all, and not merely to people with disability. This entails that, anthropologically conceptualized, vulnerability signifies an aspect of weakness, relationality and dependency. As a theological construct, it also connotes openness, relationship, dependency, belonging and flourishing.

Speaking about vulnerability as risk and openness, Thierry Collaud uses the open arms metaphor in Miroslav Volf's, Exclusion and Embrace17. In the gesture of open arms, Collaud sees a reciprocal process of being open towards the other who presents vulnerability. In accepting vulnerability (or the other), the boundary between the self and the other becomes porous, not as the power that breaks the boundaries of the other and forces the fulfillment of desire, but as a self-giving risk in this interval where the self awaits the other's answer, never being certain of it, as the other cannot be coerced or manipulated into an embrace. ${ }^{18}$

The theologian Thomas Reynolds rightly observes that emphasizing the aspects such as rational autonomy, independency, strength and individualism, the Enlightenment's anthropology fails to recognize the proper value of human integrity and, related to this, vulnerability. ${ }^{19}$

Highlighting a close link between Enlightenment premises (rational autonomy, freedom, independence and equality) and principles of liberalism (voluntarism, egalitarianism and individualism), Reynolds insist that the structures of liberal democracy, facilitate the foundation of the framework of the cult of normalcy, which became hostile towards vulnerability and disability. ${ }^{20}$

The modern comprehension of autonomy is therefore measured according to a person's rational and cognitive capacities with a strong emphasis on self-determination. This to some extent does not merely derive from the exclusive behavior of individuals with diminished rational capacities or those whose quantitative intelligence quotient fall below 75 I.Q., but derives from a rather unfortunate formulation of the notion of autonomy. This leads to the

16 Martina Vuk, "Vulnerability and Disability: Ethical and Theological Evaluation", Unpublished Research Master Thesis, KU Leuven, 2014.

17 See Miroslav Volf, Exclusion and Embrace:A Theological Exploration of Identity, Otherness and Reconciliation, (Nashville, Abingdon Press,1996), p. 99-166.

18 Thierry Collaud. "La vulnérabilité nécessaire au bien commun," (paper presented at Colloque International Personne vulnérable et société de performance, Institut Interdisciplinaire d'Ethique et des Droits de l'Homme, Université de Fribourg, Fribourg, Switzerland, April 2 2014).

19 Thomas Reynolds, Vulnerable Communion: A Theology of Disability and Hospitality, (Grand Rapids, MI: Brazos, 2008).

20 Reynolds, Vulnerable Communion, p.78-80. 
premise that not only vulnerability and autonomy need better interrelation, but as MacIntyre suggested, for an adequately balanced approach to the person, the strict separation between the two concepts, reveals the insufficient understanding of interdependency in the modern evaluation of the meaning of human person. As he puts it:

"Modern moral philosophy has understandably and rightly placed great emphasis upon individual autonomy, upon the capacity for making independent choices. Virtues of independent rational agency need for their adequate exercise to be accompanied by what I shall call the virtues of acknowledged dependence and that a failure to understand this is apt to obscure some features of rational agency." 21

Theologically speaking, vulnerability does not present an evil or tragic condition, but indicates the existential limits of earthly creatures, their interdependency, and a possibility for love.

Being made in the image of God, as indicated earlier, implies that there is a capacity to love in a charitable relationship and is inclusive of all people whatever their intellectual capacities. The intellect, as a theological aspect, does not represent a corporeal organ, and neither is mental capacity measured by its I.Q. or ability for self — determination, but is determined by its distinctive human character. I would further add that being human equally implies the capacity of being vulnerable and dependent on God and fellow humans, not as something tragic, but as a possibility for growth in and through relationships.

\section{L'Arche - an example of Christian counterculture}

In this section I will elucidate my argument by offering concrete examples of the story of the L'Arche community where people with and without disabilities are living together as friends and brothers. Such interactions imply mutual dependency that acknowledge each person's weakness and uniqueness not as something separated, but accepted and celebrated. In 2016, I interviewed a man named Brent ${ }^{22}$ who has been a friend for a long time with a person with disability in one of the L'Arche communities in England. In answering a question regarding what characterizes this friendship relationship, Brent replied:

"this friendship was a place where I could feel well, the place where I could be vulnerable; it helps me to discover that people could be my friend for reasons that were not mutual interest and mutual strengths, so this friendship brought

21 Alasdair MacIntyre, Dependent Rational Animals: Why Human Beings Need the Virtues (London: Gerald Duckworth \& Co.Ltd., 1999), p. 8.

22 In order to protect participant privacy, the given names are changed. 
me to love myself with weaknesses and imperfection and to be happy with this." ${ }^{23}$

In his answer, Brent points to a few key issues regarding the complexity of the ideas associated with the notion of vulnerability. First, Brent was a friend with a person with disability - a person whose vulnerability is (as we could assume) greater that Brent's. Second, the vulnerability of that person could possibly challenge Brent and expose his vulnerability. Third, approaching his condition as mature and responsible person, he uses terms such as vulnerability, weakness, and imperfection. And fourth, addressing the vulnerability and weakness as parts of his human condition and part of his friendship relationship does not stop him from flourishing ("to be happy").

As a Christian counterculture - founded by the 2015 Templeton Prize winner, Jean Vanier — L'Arche is a global network of communities of people with and without disability that has been a witness of a way of "transcending the barriers" between different people who live together as friends and companions for more than fifty years. Grounded in Christian principles, but explicitly multicultural and interfaith in operation, $\mathrm{L}^{\prime}$ Arche attempts to demonstrate the possibility of living by alternative values. Among other aspects, $\mathrm{L}^{\prime}$ Arche offers an alternative way of seeing the truth of disability. It is not disability as the condition per se, but the encounter with a person with disability that counts as central and authentic. Such an encounter changes how one regards the personhood and moral agency of those living with disability. The relationships within the context of L'Arche are relationships that are marked by disparity in mental capacity, in the capacity to perform certain activities, and by different social status, cultures and religions. Yet, these relationships flourish. Such relationships portray diversity as an essential element of transformative friendships. Moreover, the relationships in L'Arche are characterized by a particular way of belonging that implies interdependency, the main features of which are a narrative of vulnerability and individual uniqueness. The outcome of this interdependent relationship is transformation of a person's perception of and relation to the other, openness towards the other and mutual acceptance of one's own personal limits not as something tragic but as a way to transcend one's own self-sufficiency. Such communication and relationship has been proof demanding for mainstream society; however, it remains an opportunity to reconsider and transcend differences.

23 First name, Last name of interviewee (Exploring Friendship Relationship between People with and without Disabilities in context of L'Arche), interviewed by Martina Vuk, Manchester, England, November, 2015,transcript Martina Vuk, Université de Fribourg, Switzerland. 


\section{Conclusion}

as a point of conclusion, the encounter with the person who is fragile or different in terms of mental capacity, social status, culture and religion - such as, for instance, persons with disability, with Alzheimer's, with dementia, or who are homeless and strangers - could be the mediator of an achievement of true freedom and an opening towards a true knowledge of one - self and the other. The visible vulnerability of those ostensibly more vulnerable, reveals the invisible and hidden vulnerability of every human being and has a potential to release one - self from the captivation of false prejudices, fears and self-sufficiency.

I assume that the fundamental challenge in overcoming the fear of difference does not lie in other persons, a political system, a Church or a culture, but rather in insisting on the individuals' invulnerability, false self — image and self-sufficiency, that places barriers in the way of human communication and communion. In this regard, an anthropology founded upon recognition of vulnerability can confront cultural inconsistencies and reveal to the Church and society the possibilities for appreciating the dynamic diversity of the human condition. Thus, taking this positive approach, the concepts of disability, and relatedly human vulnerability, are not only to be understood as an exposure to suffering but also as the surrender of oneself in trust to the other and to the world.To transgress boundaries of difference that disability as a visible condition of some places in front of us, requires acceptance of our vulnerable human condition not as something tragic, but as a strength and possibility that lead us towards the other. In such exchange, the other is perceived both as a gift and a creature with the capacity to be limited and vulnerable, but simultaneously unique and autonomous in trust and dignity. 
Abstract

\section{DISABILITY AND VULNERABILITY — IMPEDIMENTS OR POSSIBILITIES?}

A Hypothesis from the scope of social Christian ethics

The visible condition of a person in bodily pain or of a person who has lost autonomy, social status or self-representation, reveals to some degree an invisible reality which is present in every human being. Assuming the validity of this premise, my primary purpose in the following paper is first to reflect upon social and cultural attitudes that consider disability and vulnerability as a boundary and a threat; and secondly, to propose an alternative in transgressing the differences of socio - anthropological boundaries in order to enable dynamic communication with fellow human beings, and ultimately, to bring about the true human flourishing. The structure of my argument is threefold. In a first part my focus is stressed upon concerns of those living with a physical condition of disability and a mainstream socio-cultural attitudes towards it. In the second part, my attention will be on the meaning of vulnerability associated with, but distinct from the notion of disability. Thirdly, I will elucidate my argument with concrete examples from the L'Arche community - where people with and without disabilities are living together in mutual interdependency and cooperation.

KEY wORDS: disability, vulnerability, self-sufficiency, L’Arche, interdependency 